\title{
Mortality from thyrotoxicosis in England and Wales and its association with the previous prevalence of endemic goitre
}

\author{
D I W PHILliPS, D J P BARKER, P D WINTER, AND C OSMOND \\ From the MRC Environmental Epidemiology Unit, Southampton General Hospital, Southampton SO9 $4 X Y$, \\ $U K$
}

SUMMARY The distribution of mortality from thyrotoxicosis among women in England and Wales during 1968-78 correlates with the previous prevalence of endemic goitre. Mortality from the disease rose to a peak in the decade $1931-40$ and then declined. This peak affected all age groups and can be attributed to the high fatality from surgery before the introduction of preoperative iodine to prevent thyroid crisis. An apparent cohort effect, whereby cohorts born from 1871 to 1886 experienced the highest mortality, may be explained by generations with a high prevalence of endemic goitre becoming exposed to increasing dietary iodine intake in later life.

Several studies have suggested that areas of the world with a high prevalence of endemic goitre have high mortality from thyrotoxicosis. ${ }^{12}$ A map of mortality from thyrotoxicosis in Britain in 1936 showed variations that correlated with the prevalence of endemic goitre. ${ }^{3}$ There have been no recent studies. The prevalence of endemic goitre in this country declined during the first half of the century. ${ }^{4}$ The purpose of the present paper is to examine whether geographical variations in current mortality from thyrotoxicosis in England and Wales are still associated with the previous distribution of endemic goitre. In addition time trends in thyrotoxicosis mortality are analysed.

\section{Methods}

The Office of Population Censuses and Surveys (OPCS) made available extracts from all 2448 death certificates in England and Wales during 1968-78 on which thyrotoxicosis was recorded as the underlying cause of death (International Classification of Disease, ICD, 8th revision number 242). As there was a major reorganisation of local authority areas in 1974 the area of residence on certificates issued after this date was coded to the pre-1974 local authority boundaries. The OPCS also provided details of all 739 deaths registered in 1976 which recorded thyrotoxicosis on any part of the certificate. An analysis of time trends in mortality during 1916-80 was based on the annual death rates from thyrotoxicosis among women in England and Wales published by OPCS. ${ }^{5}$

\section{Results}

\section{GEOGRAPHICAL DISTRIBUTION}

As during 1968-78 there were 2080 female deaths attributed to thyrotoxicosis but only 368 male deaths the analysis was restricted to women. Figure 1 shows the geographical pattern of the female deaths according to the county of residence. Mortality is expressed as standardised mortality ratios (SMRs) based on the population of England and Wales in 1971. Mortality was generally higher in the west than in the east. The highest SMRs were in Merionethshire (369) and Anglesey (353): the lowest were in Bedfordshire (39) and Yorkshire East Riding (51).

Figure 2 shows those areas in England and Wales where goitre was endemic in the past. This map, taken from the World Health Organisation's review of endemic goitre, ${ }^{4}$ was based on the two large goitre surveys in Britain undertaken in 1924 and 1948. Comparison of figs 1 and 2 shows a correlation between the previous distribution of endemic goitre and current mortality from thyrotoxicosis.

Figure 3 shows the distribution of all 628 female deaths during 1976 in which thyrotoxicosis was recorded on any part of the certificate. The rates are 305 


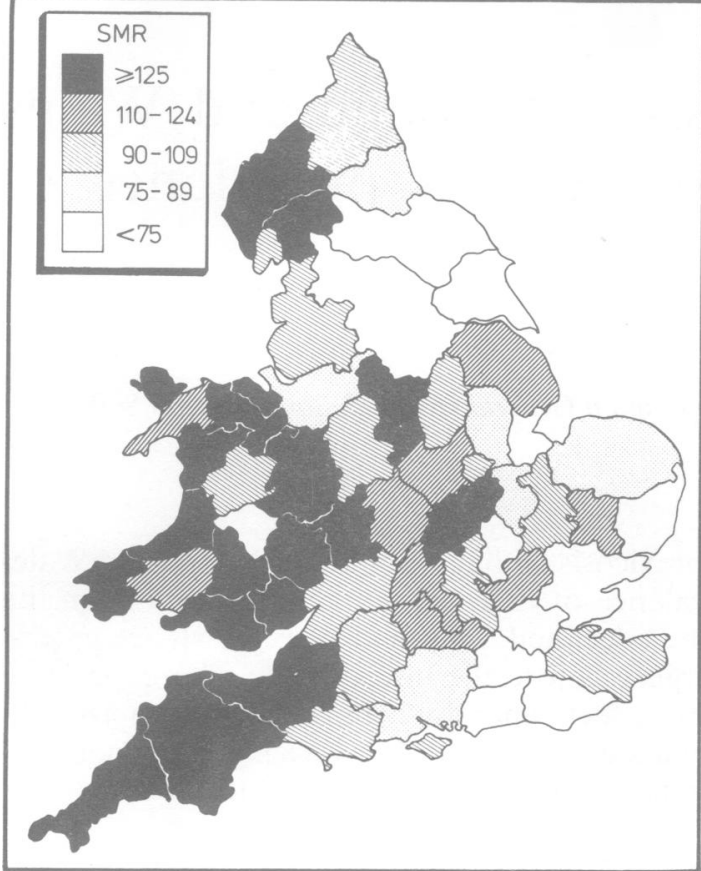

Fig 1 Mortality from thyrotoxicosis among women by county of residence in England and Wales, 1968-78. (Pre-1974 county boundaries are used.)

again expressed as SMRs. The number of deaths did not permit analysis by geographical divisions smaller than the current standard regions. The pattern, however, is broadly similar to that of fig 1 with high rates occurring in Wales and the west of England.

Table 1 is derived from the 1968-78 data, in which thyrotoxicosis is the underlying cause of death. The age-specific death rates in the two pre-1974 standard regions, Wales I and Wales II, with the highest SMRs (220 and 187 respectively) are compared with those of Yorkshire and Humberside and South Eastern I, which have the lowest SMRs (68 and 78). The coding of the data to the pre-1974 boundaries made it necessary to use the former standard regions rather than the current ones shown in fig 3 . In each of the four regions the rates increase with age. Nevertheless, the absolute difference between the death rates in the "high mortality" and "low mortality" regions is much greater among the elderly (65 years and over) than among younger people.

TIME TRENDS

Table 2 shows the mortality rates among women in England and Wales during 1916-80. They rise to a
Table 1 Average annual age specific mortality rates per million (1968-78) for thyrotoxicosis among women in regions with the highest and lowest standardised mortality ratios (see text)

\begin{tabular}{llllll}
\hline & \multicolumn{5}{c}{ Age (years) } \\
\cline { 2 - 6 } & $35-44$ & $45-54$ & $55-64$ & $65-74$ & $>75$ \\
\hline Wales I & 1.6 & 4.2 & 20.3 & 75.2 & 97.8 \\
Wales II & 8.3 & 9.3 & 17.0 & 53.4 & 76.4 \\
$\begin{array}{l}\text { Yorkshire and } \\
\text { Humberside }\end{array}$ & 2.0 & 2.7 & 6.0 & 19.9 & 29.4 \\
South Eastern I & 1.3 & 2.6 & 8.4 & 19.5 & 38.0 \\
\hline
\end{tabular}

peak in the decade 1931-40 and then decline. The relation between the age-specific rates (fig 4) is different before and after this peak. In the earlier years mortality was higher among middle aged women (45-54): after the 1930s it increased progressively with age. Variations in the death rate of a disease from year to year may be caused by changes in its incidence or case fatality, or in diagnostic and death certification practices. These will alter the

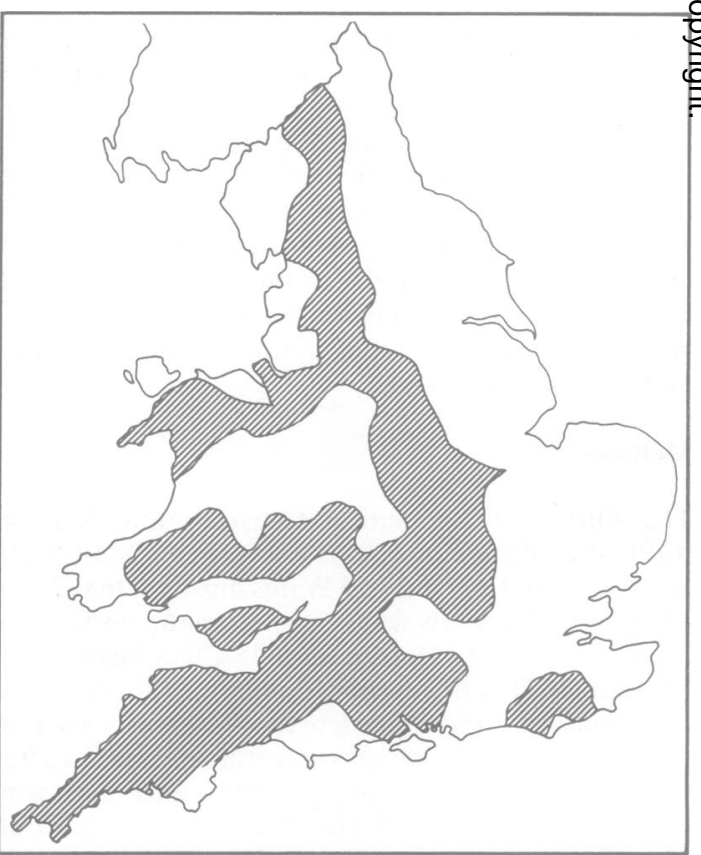

Fig 2 Areas of England and Wales where endemic goitre has been prevalent in the past. ${ }^{4}$ 
Table 2 Mortality rates from thyrotoxicosis among women in England and Wales, 1916-80. (Average annual age standardised rates per million: 1946-50 as the standard years.)

\begin{tabular}{ccccccccccccc}
\hline 1916 & $1921-$ & $1926-$ & $1931-$ & $1936-$ & $1941-$ & $1946-$ & $1951-$ & $1956-$ & $1961-$ & $1966-$ & $1971-$ & $1976-80$ \\
\hline 34.48 & 50.54 & 71.08 & 89.47 & 86.95 & 35.66 & 30.92 & 19.49 & 14.99 & 11.9 & 9.13 & 8.68 & 7.33 \\
\hline
\end{tabular}

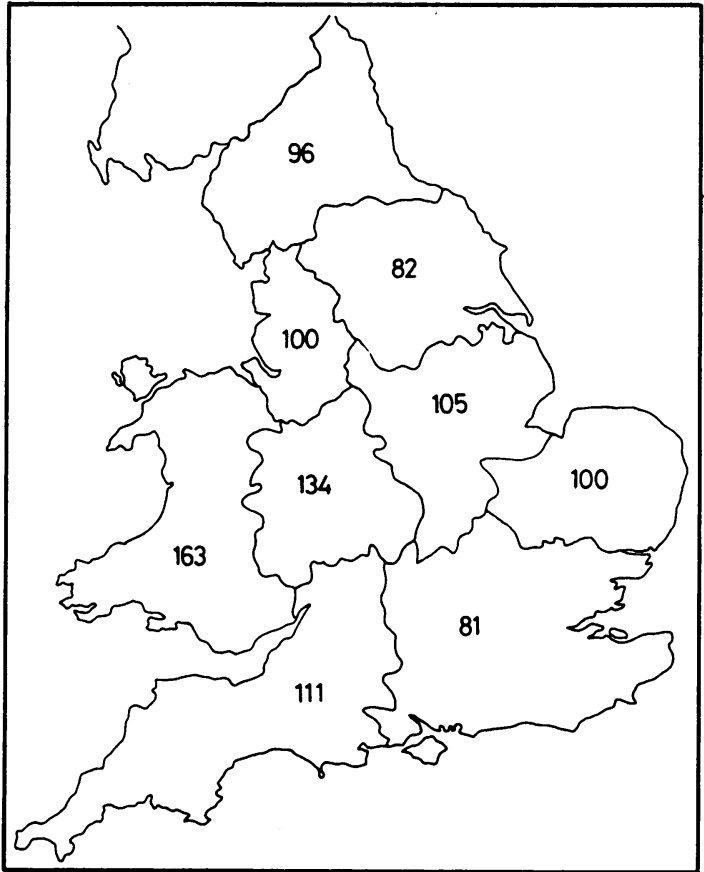

Fig 3 SMRs by region of England and Wales in 1976, based on female deaths in which thyrotoxicosis was recorded on any part of the certificate.

age-specific death rates in two major ways. Firstly, all age groups may show a similar change over a certain calendar period: this is termed a period effect. Secondly, the death rates at any particular age may change progressively in successive birth cohorts. In figure 5 the method of Osmond and Gardner ${ }^{6}$ has been used to distinguish the contribution of these two effects to the overall mortality trends. Each age-specific death rate is regarded as the product of three numbers - an age value, a period of death value, and a cohort value. The period and cohort values are given an "average" value of unity over the time span of the analysis so that the age values are similar to the overall age specific death rates. Figure 5 shows that the period of death values rise to a peak in the decade 1931-40 and then decline. The cohort

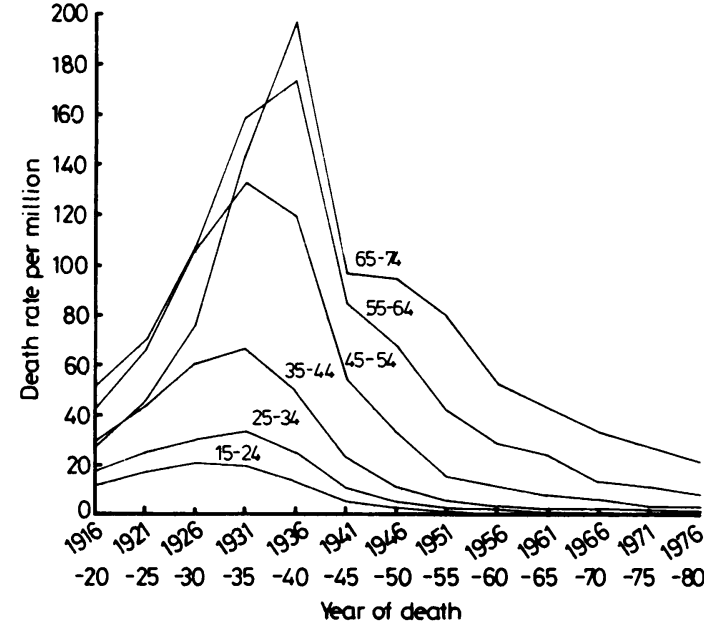

Fig 4 Age-specific mortality rates for thyrotoxicosis among women aged 15-74 (England and Wales, 1916-80).

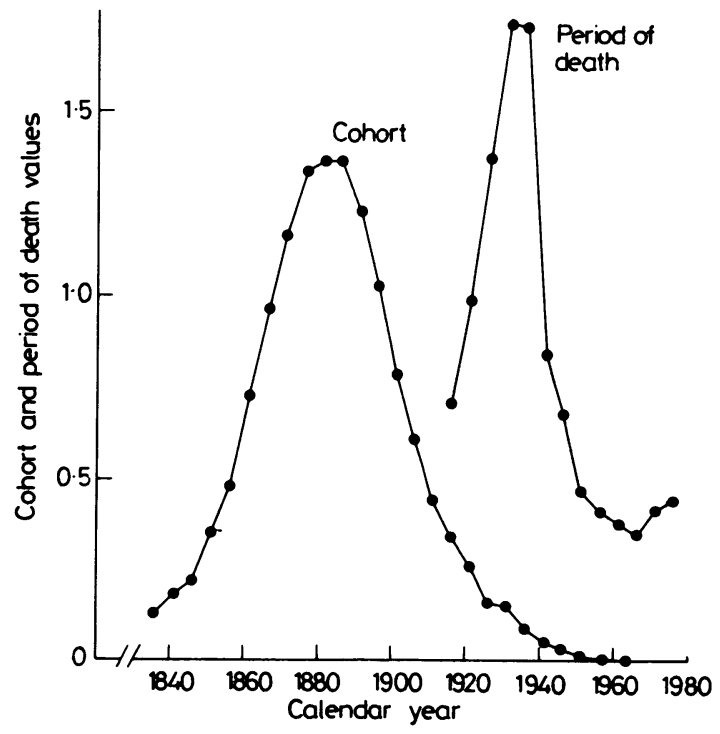

Fig 5 Cohort and period of death values for thyrotoxicosis among women aged 15-84 (England and Wales, 1916-80). 
values relate to successive generations born from 1836 to 1961 . They rise to a peak affecting the generations born from 1871 to 1886 and then continuously decline.

When the fifth revision of the ICD was adopted in 1940 the rules governing assignment of underlying cause of death were changed. Among women mortality ascribed to thyrotoxicosis fell by $12 \cdot 1 \%$. $^{7}$ Adjustment of the trends shown in fig 5 to allow for this has only a small effect. Period of death values after 1940 are raised by around $10 \%$. Cohort values change by less than 0.02 .

\section{Discussion}

Death from thyrotoxicosis is now uncommon and its immediate causes are not well documented. In a recent study of 33 deaths ${ }^{8}$ surgery was rarely a contributory factor: 20 of the patients had congestive heart failure while a further six died from various embolic episodes. Although mortality is an imperfect indicator of the current incidence of thyrotoxicosis, it seems unlikely that the large geographical variations in current mortality rates shown in fig 1 can be explained by differences in the availability or effectiveness of health care. The findings in fig 1 , based on underlying cause of death, are reinforced by those for which thyrotoxicosis was recorded on any nart of the death certificate (fig 3 ).

Information on the previous distribution of endemic goitre in England and Wales is of variable quality but the geographical pattern shown has been surprisingly consistent. The Board of Education goitre survey of 1924 was the largest single study comprising observations on 375022 children. ${ }^{9}$ Although it was based on unstandardised visual observations by school medical officers, the results agreed with earlier accounts of the prevalence of the disease. ${ }^{410}$ A Medical Research Council survey in 1948 showed that goitre was still common among both women and schoolgirls living in the areas that had been the worst affected in 1924. ${ }^{11}$ All studies have shown that endemic goitre, like thyrotoxicosis, is more prevalent among females than males.

The findings in table 1 show that the geographical differences in mortality from thyrotoxicosis are much greater among the elderly (65 years and over) than the young. Therefore it seems reasonable to conclude that there is a geographical association between the previous presence of endemic goitre and the current incidence of thyrotoxicosis among the elderly. Thyrotoxicosis in this age group is more usually caused by toxic multinodular goitre than by Graves' disease.

The rise in mortality at all ages to a peak in 1931-40 (table 2), reflected in the period of death trend in fig 5 , follows the increase in surgical treatment for thyrotoxicosis. By 1935 partial thyroidectomy had become the treatment of choice for most cases of the disease ${ }^{12}$; but it had a case fatality of up to $10 \%$ until Lugol's iodine was used to prevent

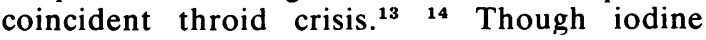
treatment was introduced in $1924,{ }^{15}$ and was popularised during the early $1930 \mathrm{~s},{ }^{16}$ there was a considerable delay in its widespread and effective use by non-specialist centres. ${ }^{17}{ }^{18}$ It is likely that the fall in mortality and the declining period of death trend after the 1930s reflects this improvement in thyroid surgery.

Since the 1930s mortality has been highest among the elderly (fig 4), who are likely to be more vulnerable to the complications of the disease and of surgical treatment. Before the 1930 s mortality was highest among the middle aged. The reason for this is not clear but it could be explained in various ways, such as a differing natural history of the disease in different age groups or differing diagnostic criteria. A pronounced period of death effect, in association with a changing age distribution of mortality, may simulate a cohort effect. Part, if not all, of the cohort effect shown in fig 5 may be accounted for in this way.

If, however, a component of the cohort effect is real there are explanations for it. Experience in Tasmania $^{19}$ and Holland ${ }^{20}$ has suggested that wheno residents of an area with a high prevalence of endemic goitre are exposed to an increase in dietary iodine intake there is an increase in the incidence of thyrotoxicosis. Although iodine supplementation of the diet was never introduced in Britain, the element is now available in a wide variety of foods. ${ }^{21}$ The average iodine intake in Britain has recently been estimated as $255 \mu \mathrm{g} /$ day, a figure substantially higher than the value of $80 \mu \mathrm{g} /$ day calculated in $1952 .{ }^{22}$ Much of this increase is due to the contamination of milk and milk products with iodine derived from animal feeds and the use of iodophor disinfectants in dairying. ${ }^{21}$

It is likely that many elderly people were iodine deficient in their youth but are now exposed to a more than adequate dietary iodine supply. They may therefore be predisposed to develop thyrotoxicosis. The cohort effect could be explained on this basis. Although endemic goitre would have been prevalent in generations born in the earlier part of the last century they were not exposed to the widespread increase in iodine intake, and were therefore not likely to develop thyrotoxicosis. The generations that were born in the latter part of the last century, however, would have been exposed in their later years to an increasing dietary iodine intake. It is these generations who experienced the highest mortality rates from thyrotoxicosis. Endemic goitre became 
less prevalent in subsequent generations who would therefore bave been less susceptible to the effect of iodine.

Requests for reprints to: Dr D I W Phillips.

\section{References}

${ }^{1}$ Clements FW. The relationship of thyrotoxicosis and carcinoma of the thyroid to endemic goitre. Med J Aust 1954; ii: 894-7.

${ }^{2}$ Prendergast W, Millmore BK, Marcus SC. Thyroid cancer and thyrotoxicosis in the United States: their relation to endemic goitre. J Chronic Dis 1961; 13: 22-37.

${ }^{3} \mathrm{McEwan}$ P. Clinical problems of thyrotoxicosis. $\mathrm{Br} \mathrm{Med} \mathrm{J}$ 1938; i: $1037-42$.

${ }^{4}$ Kelly FC, Snedden WW. Endemic goitre: prevalence and geographical distribution. In: Endemic goitre. (World Health Organisation monograph series, No 44.) Geneva: WHO, 1960: 108.

${ }^{5}$ Office of Population Censuses and Surveys. Mortality statistics, 1916-1980. London: HMSO.

${ }^{6}$ Osmond C, Gardner MJ. Age period and cohort models applied to cancer mortality rates. Statistics in Medicine 1982; 1: 245-59.

${ }^{7}$ Registrar General of England and Wales. Statistical statistics, 1916-1980. London: HMSO.

${ }^{8}$ Parker JLW, Lawson DH. Death from thyrotoxicosis. Lancet 1973; ii: 894-5.
${ }^{9}$ Stocks P. Goitre in the English school child. $Q \mathbf{J}$ Med 1928; 21: 223-75.

${ }^{10}$ Berry $\mathrm{J}$. Diseases of the thyroid gland and their surgical treatment. London: Churchill, 1901: 57-65.

${ }^{11}$ Murray MM, Ryle JA, Simpson BW, Wilson DC. Thyroid enlargement and other changes related to the mineral content of drinking water. (MRC memorandum No 18.) London: HMSO, 1948.

${ }_{12}$ Anonymous. Toxic goitre and its treatment [editorial]. Lancet 1935; i: 97-8.

${ }^{13}$ Berry J. The surgery of the thyroid gland. Lancet 1913; i: 669.

${ }^{14}$ Means JH. The thyroid and its diseases. London: Lippincott, 1937: 396.

${ }^{15}$ Plummer HS. Results of administering iodine to patients having exophthalmic goitre. JAMA 1923; 80: 1955.

${ }^{16}$ Price FW. A textbook of the practice of medicine. 4th ed. Oxford: University Press, 1933: 497.

${ }^{1 i}$ Anonymous. Planned treatment of thyrotoxicosis [editorial]. Lancet 1942; i: 263-4.

${ }^{18} \mathrm{Hill}$ IGW. Thyrotoxicosis and the results of treatment. Lancet 1938; ii: 197-8.

${ }^{10}$ Stewart JC, Vidor GI, Buttfield IH, Hetzell BS. Epidemic thyrotoxicosis in Northern Tasmania: studies of clinical features and iodine nutrition. Aust NZ J Med 1971; 3: 203-11.

${ }^{20}$ Van Leeuwen E. Form of the hyperthyroidism following use of bread made with iodised salt for goitre prophylaxis in endemic regions. Ned Tijdschr Geneesk 1954; 98: 81-6.

${ }^{21}$ Wenlock RW, Buss DH, Moxon RE, Bunton NG. Trace nutrients. 4. Iodine in British food. BrJ Nutr 1982; 47: 381-90.

${ }^{22}$ Chilean Iodine Educational Bureau. Iodine contents of foods. London: Shenval Press, 1952: 10. 